\title{
Biochemical properties and primary structure of elastase inhibitor AFUEI from Aspergillus fumigatus
}

\section{Correspondence \\ Yoshiyuki Okumura \\ kinyu@gld.mmtr.or.jp}

Received 30 November 2007

Accepted 28 February 2008

\author{
Yoshiyuki Okumura, ${ }^{1,2}$ Takeshi Matsui, ${ }^{2}$ Kenji Ogawa, ${ }^{3}$ Kei-ichi Uchiya ${ }^{2}$ \\ and Toshiaki Nikai ${ }^{2}$ \\ ${ }^{1}$ Department of Validation, Matsuurayakugyo Co. Ltd, 24-21 Enjo-chou, Syowa-ku, Nagoya, \\ Aichi 466-0054, Japan \\ ${ }^{2}$ Department of Microbiology, Faculty of Pharmacy, Meijo University, 150 Yagotoyama, \\ Tempaku-ku, Nagoya, Aichi 468-8503, Japan \\ ${ }^{3}$ Department of Pulmonary Medicine, Higashi Nagoya National Hospital, 5-101 Umemorizaka, \\ Meito-ku, Nagoya, Aichi 465-8620, Japan
}

\begin{abstract}
An elastase inhibitor from Aspergillus fumigatus (AFUEI) was isolated, and its biochemical properties and primary structure examined. The inhibitor was purified by column chromatography using DE52 cellulose and Sephadex G-75, and was found to be homogeneous as indicated by a single band following discontinuous PAGE and SDS-PAGE. A molecular mass of 7525.1 Da was observed by matrix-assisted desorption/ionization time-of-flight mass spectroscopy. The elastolytic activity of elastases from A. fumigatus, Aspergillus flavus and human leukocytes was inhibited by AFUEI. However, the elastolytic activity of porcine pancreas elastase, Pseudomonas aeruginosa elastase and elastase from snake venom was not affected by AFUEl. No inhibitory effect of DTT or 2-mercaptoethanol on the elastase inhibitory activity of AFUEI was observed. The amino acid sequence of AFUEI peptides derived from digests utilizing clostripain was determined by Edman sequencing. AFUEl was composed of 68 aa and had a calculated molecular mass of 7526.2 Da. The search for amino acid homology with other proteins demonstrated that aa 168 of AFUEl are $100 \%$ identical to aa 20-87 of the hypothetical protein AFUA $3 G 14940$ of $A$. fumigatus.
\end{abstract}

\section{INTRODUCTION}

Currently, the genus Aspergillus has been shown to comprise more than 150 species. Approximately ten species have been isolated from clinical material, in particular Aspergillus fumigatus. Aspergillosis is a common mycosis occurring in immunocompromised hosts undergoing chemotherapy. It is caused by inhalation of high concentrations of spores of the species Aspergillus. It has been reported that various proteases are produced by $A$. fumigatus (Frosco et al., 1992b; Hasegawa et al., 1995; Larcher et al., 1992; Monod et al., 1991, 1993), Aspergillus flavus (Hasegawa et al., 1997; Rhodes et al., 1990) and Aspergillus niger (Inoue et al., 1991; Takahashi et al., 1991). As $28 \%$ of lung tissue is composed of elastin, a strong correlation between elastase and the pathogenesis of aspergillosis has been suggested.

From a practical standpoint, elastase-producing strains promote a higher death rate in immunodeficient mice than

Abbreviations: GAAPLNA, glutaryl-L-alanyl-L-alanyl-L-proryl-L-leucine $p$ nitroanilide; MALDI/TOF-MS, matrix-assisted desorption/ionization time-of-flight mass spectroscopy; Pe-AFUEI, S-pyridylethylated AFUEl; $p N A, p$-nitroanilide. non-elastase-producing strains. Elastase-producing strains destroy lung tissue (Kothary et al., 1984; Reichard et al., 1990), and an elastase produced by Aspergillus has been confirmed as a virulence factor of aspergillosis (Blanco et al., 2002). We have previously studied and reported the pathogenicity of elastase produced by A. flavus in mice immunocompromised with cyclophosphamide, cyclosporine, prednisolone and carrageenan. These studies suggested that, when infected with A. flavus, a severe lesion in bronchioli or alveoli is induced by elastase-producing strains (Okumura et al., 2007a).

Ulinastatin, an elastase inhibitor, has been administered by intravenous drip infusion concomitantly with antifungal agents to patients with pulmonary aspergillosis (Hasegawa et al., 1994; Maesaki et al., 1993; Ogawa, 1997; Ogawa et al., 1992, Sugimura et al., 1994) and it has been suggested that this elastase inhibitor could be an effective therapeutic agent for aspergillosis. It has been shown that A. fumigatus and A. flavus produce elastase inhibitors (Okumura et al., 2004). We previously reported the isolation and the primary structure of an elastase inhibitor from A. flavus (Okumura et al., 2007b). In this paper, we report the isolation, biochemical properties and primary structure of 
an elastase inhibitor from A. fumigatus (strain AFU-12) from a patient.

\section{METHODS}

Strain. A. fumigatus strain AFU-12 was identified and isolated from the sputum of a patient with allergic bronchopulmonary aspergillosis. Elastases from A. fumigatus and A. flavus were purified using the method of Hasegawa et al. $(1995,1997)$.

Production of elastase inhibitor. Conidia $\left(5 \times 10^{6}\right)$ were cultured in $100 \mathrm{ml}$ synthetic medium comprising $0.1 \%$ yeast carbon base (Difco) with $1 \%$ casamino acid (Difco) as a nitrogen source. The cultures were incubated for 7 days at $37{ }^{\circ} \mathrm{C}$. The elastase inhibitory activity of the culture supernatant was measured (Fig. 1) and determined to be approximately $65-90 \%$ in culture supernatants of 4-7 days. The 7 day culture broth was filtered aseptically through a $0.22 \mu \mathrm{m}$ membrane filter and the cell-free culture supernatant was used as the crude source of inhibitor.

Discontinuous PAGE. Discontinuous PAGE was carried out on $8.5 \%$ polyacrylamide gels $\left(0.5 \times 12.5 \mathrm{~cm}, 3 \mathrm{~mA}, 4{ }^{\circ} \mathrm{C}\right)$, using $40 \mathrm{mM}$ Tris/glycine ( $\mathrm{pH} 8.3)$ as the running buffer. Gels were stained with $0.05 \%$ Coomassie brilliant blue R-250 in $1 \%$ acetic acid containing $5 \%$ methanol for $1 \mathrm{~h}$ at $48{ }^{\circ} \mathrm{C}$, followed by diffusion destaining.

Purification of AFUEl. The 7 day culture broth was applied to a column of diethylaminoethyl (DE52) cellulose (column size $2 \times 45 \mathrm{~cm}$; Whatman) equilibrated with $10 \mathrm{mM}$ Tris/ $\mathrm{HCl}(\mathrm{pH} 7.2)$ containing $10 \mathrm{mM} \mathrm{NaCl}$. The column was eluted with $10 \mathrm{mM}$ Tris/ $\mathrm{HCl}$ ( $\mathrm{pH} 7.2$ ) containing a $0-0.5 \mathrm{M} \mathrm{NaCl}$ gradient (Fig. 2a). Inhibitory activity (100-50\%) was found in fractions 232-300, which were pooled, concentrated by lyophilization and applied to a Sephadex G-75 column $(2.5 \times 100 \mathrm{~cm}$; Pharmacia $)$ equilibrated with $10 \mathrm{mM}$ Tris $/ \mathrm{HCl}$ ( $\mathrm{pH} 7.2$ ) containing $10 \mathrm{mM} \mathrm{NaCl}$. Inhibitory activity of $100 \%$ was found in fractions 115-130 (Fig. 2b). These fractions were analysed for purity by PAGE.

Assay for elastolytic inhibitory activity. The elastolytic inhibitory activity of AFUEI was assayed by the method of diazo coupling. Using $50 \mathrm{mM}$ glutaryl-L-alanyl-L-alanyl-L-proryl-L-leucine $p$-nitroanilide (GAAPLNA; Peptide Institute) in DMSO as the substrate, the amount of $p$-nitroanilide ( $p \mathrm{NA}$ ) released was measured. Fifty microlitres of AFUEI $(3 \mathrm{ng}$ ) was mixed with $50 \mu \mathrm{l}$ elastase $(30 \mathrm{ng}$ ) and the mixture was incubated for $15 \mathrm{~min}$ at $37^{\circ} \mathrm{C}$. Next, $900 \mu \mathrm{l}$

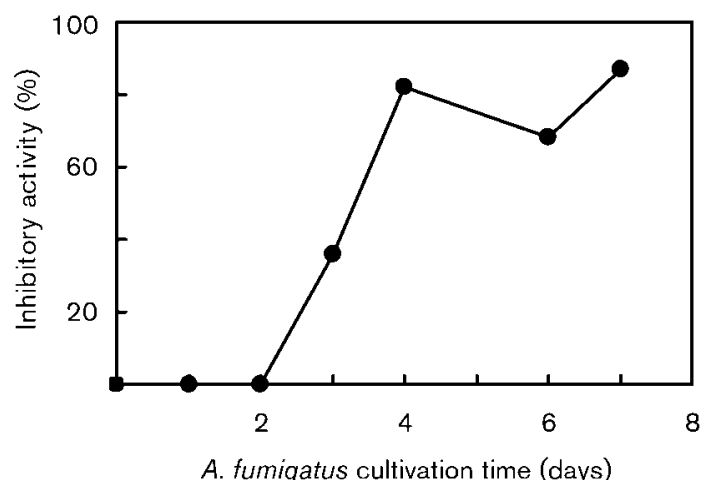

Fig. 1. Elastase inhibitory activity of $A$. fumigatus culture filtrate.
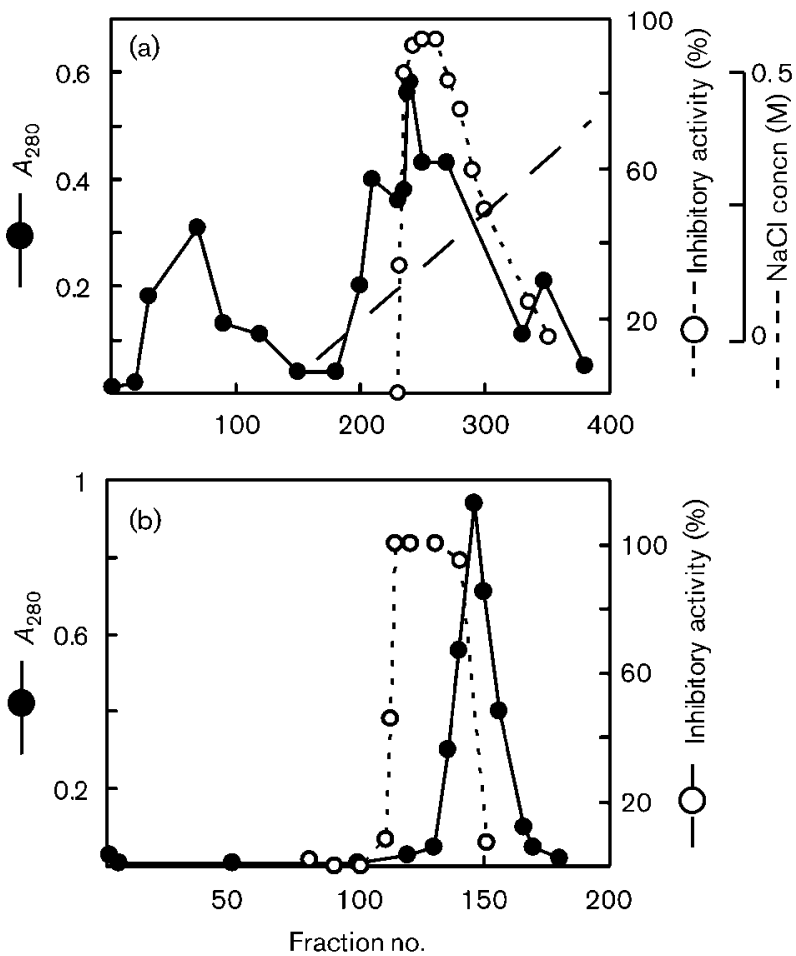

Fig. 2. Column chromatography of $A$. fumigatus culture filtrate. (a) DE52 cellulose column chromatography. A. fumigatus culture filtrate $(100 \mathrm{ml})$ was applied to a DE52 cellulose column $(2 \times 45 \mathrm{~cm})$ equilibrated with $10 \mathrm{mM}$ Tris/HCl $(\mathrm{pH} 7.2)$ containing $10 \mathrm{mM} \mathrm{NaCl}$. The column was eluted with $10 \mathrm{mM}$ Tris/ $\mathrm{HCl}$ $(\mathrm{pH} 7.2)$ containing a $0-0.5 \mathrm{M} \mathrm{NaCl}$ gradient. Fractions $(6 \mathrm{ml})$ were collected at a flow rate of $18 \mathrm{ml} \mathrm{h}^{-1}$. (b) Sephadex G-75 column chromatography. DE52 cellulose column fractions 232300 were pooled, concentrated by lyophilization and applied to a Sephadex G-75 column $(2.5 \times 100 \mathrm{~cm})$ equilibrated with $10 \mathrm{mM}$ Tris/ $\mathrm{HCl}(\mathrm{pH}$ 7.2) containing $10 \mathrm{mM} \mathrm{NaCl}$. The column was eluted with $10 \mathrm{mM}$ Tris/HCl (pH 7.2) containing $10 \mathrm{mM} \mathrm{NaCl}$. Fractions $(3 \mathrm{ml})$ were collected at a flow rate of $9 \mathrm{ml} \mathrm{h}^{-1}$.,$A_{280} ; \bigcirc$, inhibitory activity; dashed line, $\mathrm{NaCl}$ concentration.

$50 \mathrm{mM}$ Tris/ $\mathrm{HCl}$ (pH 7.5) and $20 \mu \mathrm{l} 50 \mathrm{mM}$ GAAPLNA solution were added and incubated for $60 \mathrm{~min}$ at $37{ }^{\circ} \mathrm{C}$. The reaction was stopped by adding $1 \mathrm{ml} 10 \%(\mathrm{w} / \mathrm{v})$ trichloroacetic acid. Sodium nitrite $(0.2 \mathrm{ml}, 0.1 \%), 0.2 \mathrm{ml} 0.5 \%$ ammonium sulfamate and $0.2 \mathrm{ml}$ $0.1 \%$ N-1-naphthylethylenediamine dihydrochloride were then added to the solution and the absorbance was read at $550 \mathrm{~nm}$. One unit of elastolytic inhibitory activity was defined as the amount of AFUEI (mg) that did not release pNA from GAAPLNA in $1 \mathrm{~min}$.

Effects of AFUEI on fibrinogenase and collagenase activities of elastase. Elastase from A. fumigatus in $10 \mathrm{mM}$ Tris/ $\mathrm{HCl}$ ( $\mathrm{pH} 8.5$ ) was incubated with the AFUEI supernatant for $15 \mathrm{~min}$ and then with $1 \mathrm{mg}$ fibrinogen (Katayama Chemical) or collagen (types I, II, IV and V; Wako Pure Chemical) at $37^{\circ} \mathrm{C}$ for various time intervals. Simultaneously, $100 \mu \mathrm{l}$ of the reaction mixture was pipetted into a small test tube and $100 \mu \mathrm{l}$ buffer containing $10 \mathrm{M}$ urea, $4 \%$ SDS, $10 \mathrm{mM}$ phosphate buffer ( $\mathrm{pH} 7.2)$ and $3 \% 2$-mercaptoethanol were added. This solution was incubated at $37{ }^{\circ} \mathrm{C}$ for $6 \mathrm{~h}$. An aliquot of $20 \mu \mathrm{l}$ was analysed by $12 \%$ SDS-PAGE. 
Enzymic cleavage. Native AFUEI $(40 \mu \mathrm{g})$ was digested with $5 \mu \mathrm{g}$ clostripain (Roche) for $24 \mathrm{~h}$ at $37{ }^{\circ} \mathrm{C}$ in $50 \mathrm{mM}$ Tris/ $\mathrm{HCl}$ (pH 7.2) containing $1 \%(\mathrm{v} / \mathrm{v}) 2$-mercaptoethanol and $10 \mathrm{mM} \mathrm{CaCl}_{2}$. Native AFUEI was dissolved in $1.6 \mathrm{ml} 5 \mathrm{mM}$ Tris/ $\mathrm{HCl}$ (pH 7.5) containing $8 \mathrm{M}$ urea, and $200 \mu \mathrm{l} 2$-mercaptoethanol was added to this solution. The reaction mixture was bubbled through with nitrogen for $10 \mathrm{~min}$ and incubated at $37{ }^{\circ} \mathrm{C}$ for $1 \mathrm{~h}$. 4 -Vinylpyridine $(200 \mu \mathrm{l})$ was added and the reaction mixture was stirred at room temperature for another $2 \mathrm{~h}$. The excess reagents were removed by dialysis against distilled water. S-Pyridylethylated AFUEI (Pe-AFUEI) was also digested with clostripain as above. All digests were then separated by reversed-phase HPLC using a Gilson model 302 chromatograph with a Develosil 300 ODS-HG5 column $(0.46 \times 25 \mathrm{~cm})$.

Sequence analysis. The amino acid sequence of AFUEI was analysed using an Applied Biosystems 491 protein sequencer. The phenylthiohydantoin derivatives of amino acids were identified using an Applied Biosystems model 120A PTH analyser in accordance with the manufacturer's instructions.

Determination of molecular mass. AFUEI was desalted using a ZipTip column (Millipore) and analysed by matrix-assisted desorption/ionization time-of-flight mass spectroscopy (MALDI/TOF-MS) using a Voyager PK2 (Applied Biosystems).

\section{RESULTS AND DISCUSSION}

\section{AFUEI isolation}

AFUEI was isolated from A. fumigatus by DE52 cellulose and Sephadex G-75 column chromatography as described in Methods. Fractions 115-130 (Fig. 2b) were analysed by discontinuous PAGE ( $\mathrm{pH} \mathrm{8.3)} \mathrm{and} \mathrm{SDS-PAGE} \mathrm{(Fig.} \mathrm{3),}$ and were found to be electrophoretically homogeneous. These fractions were pooled, and this preparation was designated the purified AFUEI (elastase inhibitor from $A$. fumigatus), which was used for the biochemical characterization. The total yield of purified AFUEI from $100 \mathrm{ml}$ culture supernatant was $97 \mu \mathrm{g}$.

\section{Properties of AFUEI}

The molecular mass of the inhibitor isolated from $A$. fumigatus was $7525.1 \mathrm{Da}$ as determined by MALDI/TOFMS (Fig. 4). The carbohydrate content of AFUEI was calculated to be $0 \%$ with glucose as a standard using the method of Morris (1948). The heat stability of AFUEI $(0.1 \mu \mathrm{g})$ in $10 \mathrm{mM}$ Tris/ $\mathrm{HCl}(\mathrm{pH} 7.5)$ containing $10 \mathrm{mM}$ $\mathrm{NaCl}$ was investigated. The inhibitor was heated for $10 \mathrm{~min}$ at $37,50,60,80$ and $100{ }^{\circ} \mathrm{C}$, cooled quickly to $4{ }^{\circ} \mathrm{C}$ and the inhibitory activity was determined. AFUEI was stable to heat treatment, retaining $33.3 \%$ activity after treatment at $100{ }^{\circ} \mathrm{C}$. The effect of reducing agents on AFUEI was also determined. AFUEI was mixed with the reducing agent and incubated for $15 \mathrm{~min}$ at $37{ }^{\circ} \mathrm{C}$ prior to the addition of GAAPLNA as substrate to determine whether reduction had an effect on its inhibitory activity. AFUEI activity was not inhibited by $2.5 \mathrm{mM}$ DTT or $1.9 \mathrm{mM}$ 2-mercaptoethanol.

The effect of AFUEI on various elastases was determined and is shown in Table 1. Elastases from A. fumigatus,

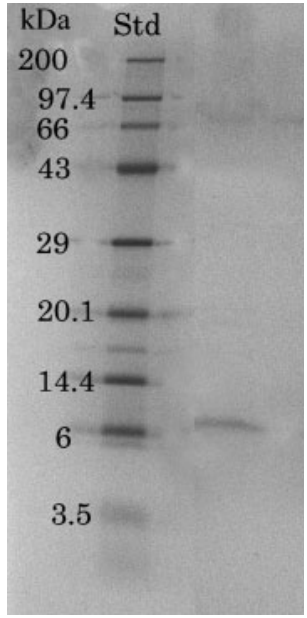

Fig. 3. SDS-PAGE of purified AFUEI. SDS-PAGE was performed using the method of Weber \& Osborn (1969). Protein standards used were insulin $B$ chain $(3.5 \mathrm{kDa})$, aprotinin $(6 \mathrm{kDa})$, lysozyme $(14.4 \mathrm{kDa})$, soybean trypsin inhibitor $(20.1 \mathrm{kDa})$, carbonic anhydrase $(29 \mathrm{kDa})$, ovalbumin $(43 \mathrm{kDa}), \mathrm{BSA}(66 \mathrm{kDa})$, phosphorylase $b(97.4 \mathrm{kDa})$ and myosin $(200 \mathrm{kDa})$. AFUEl was treated with $4.3 \%$ SDS, reduced with $10 \% 2$-mercaptoethanol for $3 \mathrm{~min}$ at $100^{\circ} \mathrm{C}$ and then run on a polyacrylamide gel (MULTIGEL II Mini 15/25; Daiichi Pure Chemicals).

A. flavus, human leukocytes and porcine pancreas were inhibited 100, 98.9, 83.8 and $11.7 \%$ by AFUEI, respectively. However, Pseudomonas aeruginosa (Komori et al., 2001) and snake venom elastases were not inhibited. The effects of AFUEI on the fibrinogenase and collagenase activities of elastase from A. fumigatus were measured. Both activities of the elastase were completely inhibited by AFUEI. The Michaelis constant $\left(K_{\mathrm{m}}\right)$ for GAAPLNA of elastase from $A$. fumigatus at $\mathrm{pH} 7.5$ was $3.8 \times 10^{2} \mu \mathrm{M}$. The inhibition constant $\left(K_{\mathrm{i}}\right)$ of AFUEI for elastase was determined by

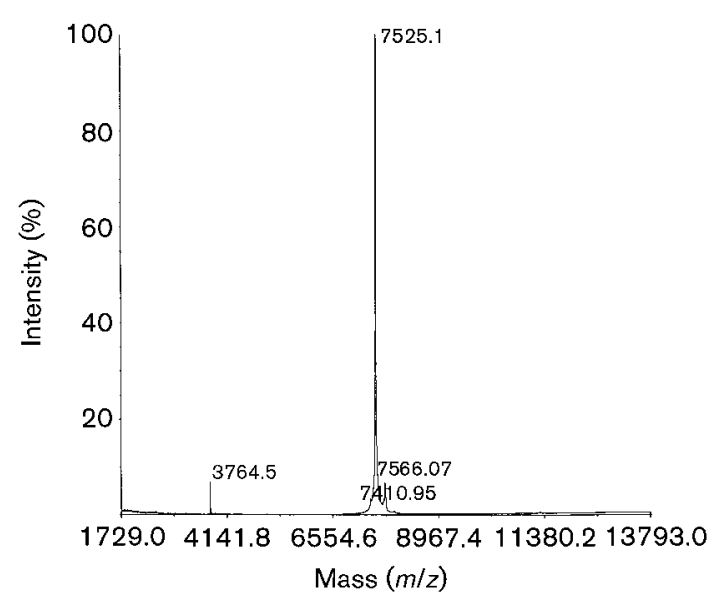

Fig. 4. MALDI-TOF MS results for AFUEI. 
Table 1. Inhibitory activity of AFUEI on elastases

\begin{tabular}{|llc|}
\hline Elastase/proteinase & Substrate & Inhibitory activity (\%) \\
\hline Purified elastase from A. fumigatus & GAAPLNA & 100.0 \\
Purified elastase from A. flavus & GAAPLNA & 98.9 \\
Purified elastase from human leukocytes & SAPANA & 83.8 \\
Purified elastase from porcine pancreas & STANA & 11.7 \\
Elastase from P. aeruginosa & GAAPLNA & 0 \\
Elastase from Crotalus atrox venom & STANA & 1.7 \\
Fibrinogenase activity of elastase from A. fumigatus & Fibrinogen & IN \\
Collagenase activity of elastase from A. fumigatus & Collagen (types I, II, IV and V) & IN \\
\hline
\end{tabular}

IN, Complete inhibition; SAPANA, succinyl-Ala-Pro-Ala- $p$ NA; STANA, succinyl-Ala-Ala-Ala- $p$ NA.

measuring the initial rate of hydrolysis of GAAPLNA at $\mathrm{pH}$ 7.5. The inhibition of AFUEI was non-competitive and an inhibition constant of $1.6 \times 10^{-3} \mu \mathrm{M}$ was obtained.

\section{Primary structure of AFUEI}

The first 44 residues of AFUEI were determined by $\mathrm{N}$ terminal sequence analysis (Fig. 5). AFUEI was incubated with clostripain. The digested fragments were purified by reversed-phase HPLC (Fig. 6a) and their sequences analysed (Table 2). Pe-AFUEI was also incubated with clostripain and analysed by reversed-phase HPLC (Fig. 6b), and the amino acid sequence of each fragment (Pe-R-1 and Pe-R-2) was examined (Fig. 5). The AFUEI sequence showed two cysteinyl residues. From these results, a total of 68 aa residues of AFUEI were identified (Fig. 5). Thus, AFUEI is composed of 68 aa and the molecular mass of the protein portion of AFUEI was estimated to be $7526.2 \mathrm{Da}$. The molecular mass of AFUEI based on the amino acid sequence was identical to the molecular mass obtained by MALDI/TOF-MS. The hypothetical protein AFUA 3G14940 of A. fumigatus has been reported (Nierman et al., 2005) and its amino acid sequence from aa 20 to 87

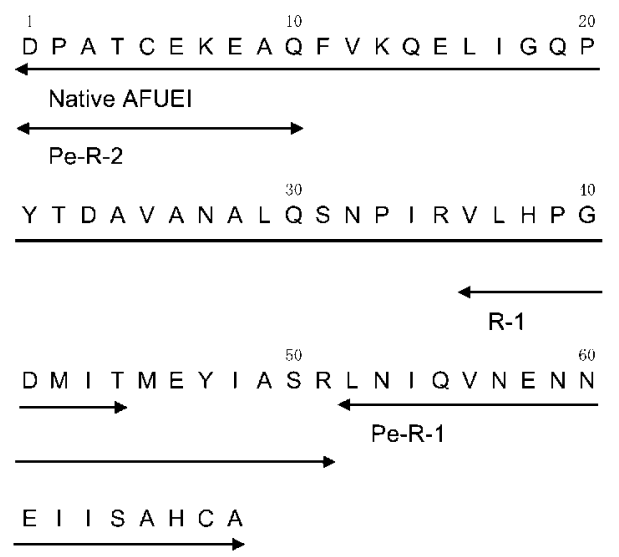

Fig. 5. Amino acid sequence of AFUEl. Arrows indicate residues determined by sequence analysis. was found to be identical to aa 1-68 of AFUEI. It is likely that this hypothetical protein also has an inhibitory activity. No tryptophan residue was found and a total of three aromatic amino acids (two tyrosines and one phenylalanine) were present. As a result, the absorption at $280 \mathrm{~nm}$ was minimal (Fig. 2b).

\section{Comparison with other protease inhibitors}

Comparative studies of the inhibitory activity of AFUEI with four other protease inhibitors were performed (Table 2). Ulinastatin, nafamostat mesilate, sivelestat sodium hydrate and gabexate mesilate are proteinase inhibitors normally used for the treatment of acute pancreatitis, acute lung disturbance and intravascular coagulation disease. Our results showed that AFUEI inhibited elastase from $A$. fumigatus. Inhibition by nafamostat mesilate was also observed; however, all four protease inhibitors demonstrated very weak inhibitory activity in comparison with AFUEI. These results clearly demonstrated that AFUEI has a strong inhibitory effect on elastase from A. fumigatus and that only low concentrations of AFUEI are needed for inhibition.

Aspergillosis is a common mycosis occurring in immunocompromised hosts undergoing chemotherapy. The pathogenesis of aspergillosis is not clearly understood. However, the published results on pathogenesis strongly indicate that proteases are significant factors in the pathogenic process. Several of these proteases have been isolated: Frosco et al. (1992a) purified an elastase of $32000 \mathrm{Da}$ from A. fumigatus that was inhibited by EDTA, Monod et al. (1991) purified an alkaline protease of $33000 \mathrm{Da}$, Rhodes et al. (1990) purified an elastolytic protease of $23000 \mathrm{Da}$ from A. flavus, and Kolattukudy et al. (1993) purified an elastolytic serine protease of $33000 \mathrm{Da}$ from A. fumigatus and determined the primary structure by using an elastin medium. The latter study compared the lethal activity of the elastaseproducing and non-elastase producing strains and reported that the former exhibited lethal activity. They also found that the non-elastase-producing strain possessed lethal activity, but this was at a negligible minimum level. Kothary et al. (1984) compared the lethal activity of six elastase-producing strains and four non-elastase-producing 

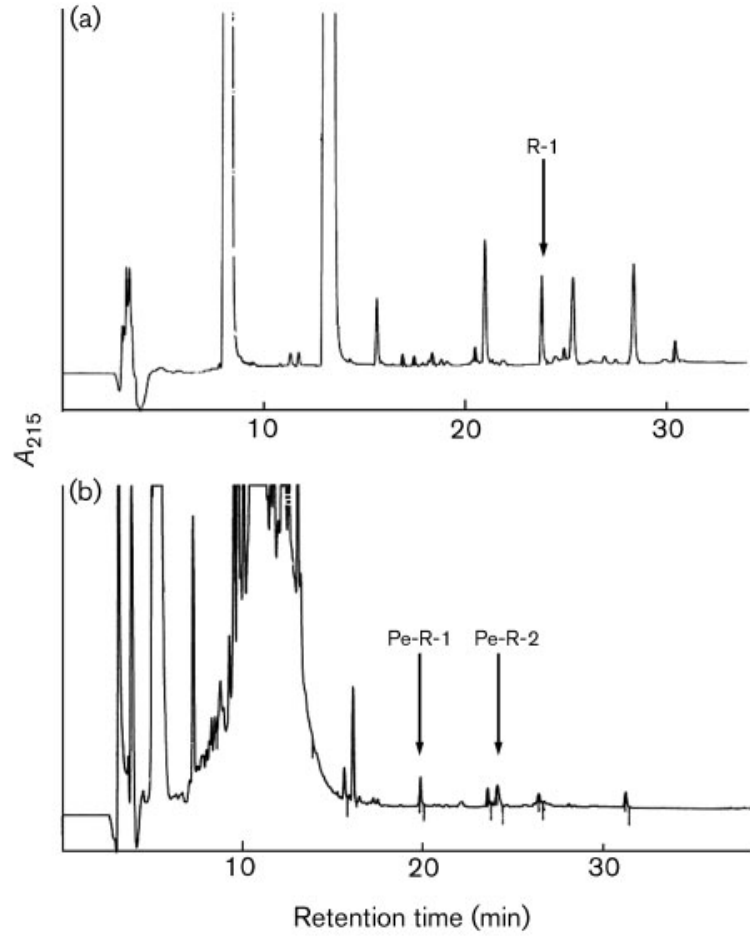

Fig. 6. Reversed-phase HPLC fractionation of the peptides obtained by clostripain cleavage of AFUEI. Native AFUEI (a) or Pe-AFUEI (b) was incubated with clostripain and aliquots were taken for analysis by reversed-phase HPLC using a Develosil 300 ODS-HG- 5 column $(0.46 \times 25 \mathrm{~cm})$. Solvent $A$ was $0.1 \%$ trifluoroacetic acid (TFA) in $\mathrm{H}_{2} \mathrm{O}$, solvent $\mathrm{B}$ was $0.1 \%$ TFA in acetonitrile and the flow rate was $1.0 \mathrm{ml} \mathrm{min}{ }^{-1}$. Elution was achieved over 60 min with a linear gradient from 0 to $100 \%$ using solvent B.

strains of A. fumigatus. Their results were comparable to those of Kolattukudy et al. (1993). Furthermore, when the dead murine pulmonary tissue was examined, it was found that elastase-producing strains had broadly invaded the tissue more than non-elastase-producing strains. Monod et al. (1991) reported a similar result with an alkaline protease-deficient mutant, and Blanco et al. (2002) presented results on the participation of elastase in pathogenicity. As lung tissue contains large amounts of elastin, we focused on elastase as a factor of infection. Our laboratory purified an elastolytic protease from $A$.

Table 2. Effect of various inhibitors on elastase from $A$. fumigatus

\begin{tabular}{|lc|}
\hline Inhibitor & IC $_{\mathbf{5 0}}(\boldsymbol{\mu g})$ \\
\hline AFUEI & 0.0026 \\
Ulinastatin & $>830$ \\
Nafamostat mesilate & 72 \\
Sivelestat sodium hydrate & $>500$ \\
Gabexate mesilate & 2000 \\
\hline
\end{tabular}

fumigatus with a molecular mass of $32000 \mathrm{Da}$ and $\mathrm{pI}$ of 9.1 (Hasegawa et al., 1995) that has been shown to cause pathogenicity. Additionally, we purified an elastolytic glycoprotein protease from $A$. flavus that was inhibited by diisopropyl fluorophosphate. This protease had a molecular mass of $40000 \mathrm{Da}$ and $\mathrm{pI}$ of 8.6 (Hasegawa et al., 1997) and has also been shown to cause pathogenicity (Okumura et al., 2007a). It is clear from these results that elastases are related to pathogenicity and therefore that an elastase inhibitor could be an important treatment for aspergillosis.

In a previous report, screening of the elastase inhibitor from Aspergillus was conducted and it was found that both A. fumigatus and A. flavus produced an elastase inhibitor (Okumura et al., 2004). In addition, both the elastase activity and inhibitory activity of the AFU-12 strain were found to be stronger than those in the previous 13 strains used. In this report, the elastase inhibitor from $A$. fumigatus (AFUEI) was purified, and its biochemical properties and primary structure examined.

Development of a substance that inhibits leukocyte elastase for the purpose of suppressing internal inflammation is a current focus. For example, ONO-5046 (Kawabata et al., 1991) is used for the treatment of acute lung disturbance with a general inflammatory reaction symptom complex. The results of our studies reveal an inhibitor capable of inhibiting leukocyte elastase. AFUEI is therefore a promising agent for suppressing inflammatory diseases effectively, as it is a potent inhibitor of human leukocyte elastase.

Elastase from A. fumigatus displays strong degrading effects on fibrinogen and collagen (types I, II, IV and V). AFUEI strongly inhibited the activity of the elastase and therefore could prevent the degrading effect of A. fumigatus on fibrinogen and collagen. Type IV collagen is the main component of the basal membrane of blood vessels and alveoli, and the bleeding seen on histopathological examination is thought to be caused by injury to the basal membrane of these structures. Moreover, elastase has an injurious effect locally at the infection site, and is thought to be related in some way to the pathogenicity manifested by the tissue infiltration and inflammation exhibited by $A$. fumigatus. Taken together, these findings suggest that AFUEI inhibits tissue infiltration and inflammation seen with aspergillosis and thereby weakens pathogenicity. Ogawa et al. (1992) reported a clinical effect with the protease inhibitor ulinastatin. When ulinastatin was administered to a patient with lung aspergillosis who had recurrent haemoptysis and haemosputum, the symptoms disappeared within a short period. Maesaki et al. (1993) and Sugimura et al. (1994) reported that cases of pulmonary aspergilloma and invasive pulmonary aspergillosis were successfully treated with the combined use of ulinastatin and amphotericin B.

The elastase inhibitor from A. flavus (AFLEI) has been purified and its biochemical properties and primary structure examined previously (Okumura et al., 2006, 
2007b). The biochemical properties and primary structure of AFUEI were identical to AFLEI. It is interesting that $A$. fumigatus and $A$. flavus produce elastase inhibitors with the same primary structure. Most cases of aspergillosis are caused by $A$. fumigatus and A. flavus. If AFUEI inhibits elastases from A. fumigatus and A. flavus in vivo, it is predicted that AFUEI will be an effective agent against most cases of aspergillosis.

\section{REFERENCES}

Blanco, J. L., Hontecillas, R., Bouza, E., Blanco, I., Pelaez, T., Munoz, P., Molina, J. P. \& Garcia, M. E. (2002). Correlation between the elastase activity index and invasiveness of clinical isolates of Aspergillus fumigatus. J Clin Microbiol 40, 1811-1813.

Frosco, M., Chase, T., Jr \& Macmillan, J. D. (1992a). Purification and properties of the elastase from Aspergillus fumigatus. Infect Immun 60, 728-734.

Frosco, M., Fahed, C., Chase, T., Jr \& Macmillan, J. D. (1992b). Inhibition of Aspergillus fumigatus elastase with monoclonal antibodies produced by using denatured elastase as an immunogen. Infect Immun 60, 735-741.

Hasegawa, Y., Nikai, T., Yoshikawa, Y., Sugihara, H., Ogawa, K. \& Takagi, K. (1994). Elastase activity from Aspergillus species and inhibition by ulinastatin. Jap J Med Mycol 35, 293-298.

Hasegawa, Y., Nikai, T., Yamashita, R., Yoshikawa, Y., Sugihara, H., Ogawa, K. \& Mizuno, M. (1995). Isolation and characterization of elastolytic proteinase from Aspergillus fumigatus. Jap J Med Mycol 36, 235-243.

Hasegawa, Y., Nikai, T., Okumura, Y., Ogawa, K. \& Sugihara, H. (1997). Characterization of elastolytic proteinase from Aspergillus flavus: comparison of the elastolytic proteinase from Aspergillus fumigatus. Jap J Med Mycol 38, 53-59.

Inoue, H., Kimura, T., Kitahara, S., Makabe, O. \& Takahashi, K. (1991). The gene and deduced protein sequences of the zymogene of Aspergillus niger acid proteinase A. J Biol Chem 266, 19484-19489.

Kawabata, K., Suzuki, M., Sugitani, M., Imaki, K., Toda, M. \& Miyamoto, T. (1991). ONO-5046, a novel inhibitor of human neutrophil elastase. Biochem Biophys Res Commun 177, 814-820.

Kolattukudy, P. E., Lee, J. D., Rogers, L. M., Zimmerman, P., Ceselski, S., Fox, B., Stein, B. \& Copelan, E. A. (1993). Evidence for possible involvement of an elastolytic serine protease in aspergillosis. Infect Immun 61, 2357-2368.

Komori, Y., Nonogaki, T. \& Nikai, T. (2001). Hemorrhagic activity and muscle damaging effect of Pseudomonas aeruginosa metalloproteinase (elastase). Toxicon 39, 1327-1332.

Kothary, M. H., Chase, T., Jr \& Macmillan, J. D. (1984). Correlation of elastase production by some strains of Aspergillus fumigatus with ability to cause pulmonary invasive aspergillosis in mice. Infect Immun 43, 320-325.

Larcher, G., Bouchara, J. P., Annaix, V., Symoens, F., Chabasse, D. \& Tronchin, G. (1992). Purification and characterization of a fibrinogenolytic serine proteinase from Aspergillus fumigatus culture filtrate. FEBS Lett 308, 65-69.
Maesaki, S., Kohno, S., Tanaka, K., Miyazaki, H., Mitsutake, K., Miyazaki, T., Tomono, K., Kaku, M., Koga, H. \& Hara, K. (1993). A case of pulmonary aspergilloma successfully treated with combination therapy of intracavitary injection of amphotericin B and intravenous administration of urinastatin. Nihon Kyobu Shikkan Gakkai Zasshi 31, 1327-1331 (in Japanese).

Monod, M., Togni, G., Rahalison, L. \& Frenk, E. (1991). Isolation and characterization of an extracellular alkaline protease of Aspergillus fumigatus. J Med Microbiol 35, 23-28.

Monod, M., Paris, S., Sangland, D., Jaton-Ogay, K., Bille, J. \& Latge, J. P. (1993). Isolation and characterization of secreted metalloprotease of Aspergillus fumigatus. Infect Immun 61, 4099-4104.

Morris, D. L. (1948). Quantitative determination of carbohydrates with Dreywood's anthrone reagent. Science 107, 254-255.

Nierman, W. C., Pain, A., Anderson, M. J., Wortman, J. R., Kim, H. S., Arroyo, J., Berriman, M., Abe, K., Archer, D. B. \& other authors (2005). Genomic sequence of the pathogenic and allergenic filamentous fungus Aspergillus fumigatus. Nature 438, 1151-1156.

Ogawa, K. (1997). Treatment of chronic pulmonary aspergillosis. Kekkaku 72, 59-64 (in Japanese).

Ogawa, K., Taki, F., Takagi, K., Furui, H., Tsuda, M., Honda, K., Sasaki, T., Sasamoto, M. \& Miwa, T. (1992). Study of elastase production by Aspergillus species and inhibition of their elastase activity by drugs. Kokyuu 11, 880-886 (in Japanese).

Okumura, Y., Ogawa, K. \& Nikai, T. (2004). Elastase and elastase inhibitor from Aspergillus fumigatus, Aspergillus flavus and Aspergillus niger. J Med Microbiol 53, 351-354.

Okumura, Y., Ogawa, K., Uchiya, K. \& Nikai, T. (2006). Isolation and characterization of a novel elastase inhibitor, AFLEI from Aspergillus flavus. Jap J Med Mycol 47, 219-224.

Okumura, Y., Ogawa, K. \& Nikai, T. (2007a). Pathogenicity of elastase from Aspergillus flavus. J Res Inst Meijo Univ 6, 145-152 (in Japanese).

Okumura, Y., Ogawa, K., Uchiya, K. \& Nikai, T. (2007b). Characterization and primary structure of elastase inhibitor, AFLEI, from Aspergillus flavus. Jap J Med Mycol 48, 13-18.

Reichard, U., Buttner, S., Eiffert, H., Staib, F. \& Ruchel, R. (1990). Purification and characterization of an extracellular serine proteinase from Aspergillus fumigatus and its detection in tissue. J Med Microbiol 33, 243-251.

Rhodes, J. C., Amlung, T. W. \& Miller, M. S. (1990). Isolation and characterization of an elastinolytic proteinase from Aspergillus flavus. Infect Immun 58, 2529-2534.

Sugimura, S., Yoshida, K., Oba, H., Hashiguchi, K., Nakajima, M., Moriya, O., Okimoto, N., Niki, Y. \& Soejima, R. (1994). Two cases of invasive pulmonary aspergillosis in non-immunocompromised hosts. Nihon Kyobu Shikkan Gakkai Zasshi 32, 1032-1037 (in Japanese).

Takahashi, K., Inoue, H., Sakai, K., Kohama, T., Kitahara, S., Takishima, K., Tanji, M., Athauda, S., Takahashi, T. \& other authors (1991). The primary structure of Aspergillus niger acid proteinase A. J Biol Chem 266, 19480-19483.

Weber, K. \& Osborn, M. (1969). The reliability of molecular weight determination by dodecyl sulphate-polyacrylamide gel electrophoresis. J Biol Chem 244, 4406-4412. 